\title{
Profiles of dissolved organic matter and haloacetic acid formation potential in drinking water treatment by a comprehensive fractionation technique
}

\author{
$\operatorname{AUTHOR(S):~}$ \\ Jo, I.; Echigo, S.; Itoh, S.
}

\section{CITATION:}

Jo, I. ... [et al]. Profiles of dissolved organic matter and haloacetic acid formation potential in drinking water treatment by a comprehensive fractionation technique. Water Science \& Technology: Water Supply 2012, 13(1): 89-95

ISSUE DATE:

2012-12

URL:

http://hdl.handle.net/2433/187127

\section{RIGHT:}

The definitive peer-reviewed and edited

version of this article is published in 'Water Science and Technology: Water Supply. 13(1), 89-95 (2013),

doi:10.2166/ws.2012.082' and is available at www.iwapublishing.com.”; この論文は出版社版でありません。引用の際に は出版社版をご確認ご利用ください。; This is not the published version. Please cite only the published version. 


\title{
Profiles of Dissolved Organic Matter and Haloacetic Acid Formation Potential along Drinking Water Treatment by a Comprehensive Fractionation Technique
}

\author{
I. Jo*, S. Echigo**, S. Itoh** \\ * Kyoto City Waterworks Bureau, Minamiku, Kyoto 601-8004, Japan \\ (E-mail: ik.jyo@suido.city.kyoto.jp) \\ ** Graduate School of Global Environmental Studies, Kyoto University, Nishikyoku, Kyoto 615-8540, Japan \\ (E-mail:echigo@urban.env.kyoto-u.ac.jp)
}

\begin{abstract}
A comprehensive fractionation technique was applied to a set of water samples obtained along a real drinking water treatment plant with ozonation and granular activated carbon (GAC) treatment to obtain detailed profiles of dissolved organic matter (DOM) and to evaluate the haloacetic acid (HAA) formation potentials of these DOM fractions. The results indicated that ozonation and GAC treatment showed limited ability to remove hydrophilic fractions (23\%), while removal of hydrophobic fractions was $72 \%$. The contribution of hydrophilic fractions to HAA formation increased from $30 \%$ to $61 \%$ along the treatment train because of better removal for hydrophobic fractions both in concentration and reactivity. Similar trends were also found for trihalomethanes.
\end{abstract}

Keywords

Dissolved organic matters; disinfection byproducts; fractionation; haloacetic acids

\section{INTRODUCTION}

The precursors of disinfection byproducts (DBPs) - toxic compounds produced by the reaction between disinfectants and organic or inorganic constituents in source water-were believed to be mainly hydrophobic compounds (i.e., humic and fulvic acids). However, recent studies have suggested that the hydrophilic fraction is a major contributor to the formation of trihalomethanes (THMs, $\mathrm{CHX}_{3}$, where $\mathrm{X}=\mathrm{Cl}, \mathrm{Br}$, or I) (Imai et al., 2003). THM formation potential per unit of dissolved organic carbon (DOC) from hydrophilic fraction was shown to be comparable to that of aquatic humic substances (hydrophobic fraction), and the hydrophilic fraction could be a dominant precursor of THMs for low humic waters. Nagai et al. (2005) also found that the hydrophilic fraction of lake dissolved organic matter (DOM) was a major precursor of THMs. These and other studies clearly highlighted the importance of hydrophilic fractions for DBP formation, and have changed our view of DBP precursors.

This may also be true for other DBPs. Indeed, it has been reported that hydrophilic fraction could be a major precursor of haloacetic acids (HAAs, $\mathrm{CH}_{3-n} \mathrm{X}_{n} \mathrm{COOH}$, where $\mathrm{X}=\mathrm{Cl}, \mathrm{Br}$, or I), another important class of DBPs (Liang and Singer, 2003; Lu et al., 2009). In addition, the contribution of the hydrophilic fraction is significant for the formation of dichloroacetonitrile and $\mathrm{N}$ nitrosodimethylamine (NDMA) (Lee et al., 2007). These findings suggest that hydrophilic fractions are important as precursors of various DBPs.

Most of the studies mentioned above focused on characterization of DOM and on evaluation of the DBP formation potentials of raw waters. However, the composition of DOM changes along the treatment system and the major precursors of DBPs could depend on the type of drinking water treatment. Thus, it is desirable to characterize DOM after treatment to identify the major fractions contributing to DBP formation in actual drinking water. Kim and $\mathrm{Yu}$ (2005) compared DOC profiles and DBP formation potentials between conventional rapid sand filtration and membrane treatment systems (ultrafiltration and nanofiltration). While this was a major advance in the field of DBP chemistry, their evaluation did not include ozonation, a key treatment step in advanced drinking water treatment plants. In addition, DOM was divided into only two fractions (hydrophilic and hydrophobic). 
The combination of ozonation and granular activated carbon (GAC) is a common and effective approach to control DBPs. However, to our knowledge, there have been no detailed reports regarding the DOM profile (e.g., the percentage of hydrophilic fraction) along the treatment train with ozonation and GAC treatment, or how the most important fractions for DBP formation shift with each unit operation. While both THMs $(0.06,0.03,0.1,0.09$, and $0.1 \mathrm{mg} / \mathrm{L}$ for chloroform, bromodichloromethane, dibromochloromethane, bromoform, and total trihalomethanes, respectively) and HAAs $(0.02,0.04$, and $0.2 \mathrm{mg} / \mathrm{L}$ for chloroacetic acid, dichloroacetic acid, and trichloroacetic acid, respectively) are regulated as chlorination byproducts in Japan, much less information is available for HAAs. In the present study, we applied a comprehensive fractionation technique of DOM to a set of water samples obtained along a real drinking water treatment plant with ozonation and GAC treatment, and evaluated the HAA formation potentials of these DOM fractions to identify the major precursors at each treatment step. THM formation potentials were also measured for comparison.

\section{MATERIALS AND METHODS}

\section{Water samples}

Water samples were collected at an actual drinking water plant in the Osaka area, Japan, on December 17, 2007. The $\mathrm{pH}$, bromide ion concentration, DOC, and specific UV absorbance (SUVA) at $258 \mathrm{~nm}$ of the source water were $7.3,32 \mu \mathrm{g} / \mathrm{L}, 2.5 \mathrm{mg} / \mathrm{L}$, and $2.7 \mathrm{~L} /(\mathrm{m} \cdot \mathrm{mg}$ ), respectively. This plant employs ozonation (ozone dose: $0.3-0.5 \mathrm{mg} / \mathrm{L}$ on the day of sampling) and GAC treatment (contact time: $24 \mathrm{~min}$ ) after coagulation with polyaluminum chloride (PAC), sedimentation, and rapid sand filtration. Four samples were collected in this study: inlet, after sand filtration, ozonation, and GAC.

\section{Fractionation}

The samples were fractionated into six fractions by a method similar to that described previously by Leenheer (2004). In our experiment, no colloidal fraction was isolated. The method consisted of a series of adsorption onto DAX-8 resin (Supelco), XAD-4 resin (Supelco), and ion-exchange resins (Marathon MSA-1 and MSC-1; Dowex) under several different $\mathrm{pH}$ conditions (Figure 1). As a small but non-negligible level of bromide ions was found in hydrochloric acid and sodium chloride used in this study, sulfuric acid and sodium sulfate were used for desorption and $\mathrm{pH}$ adjustment. The fractions obtained by this procedure were hydrophobic acid (HoA), hydrophobic neutral (HoN), transphilic acid and neutral (Trs), base (Bas), hydrophilic acid (HiA), and hydrophilic neutral (HiN). These fractions were used for evaluation of HAA formation potentials without further purification (i.e., desalting).

\section{Chlorination}

Chlorination of each DOM fraction was performed at $\mathrm{pH}$ 7.0. Other conditions were as follows: chlorine dose, $3 \mathrm{mg} / \mathrm{L}$; DOC, $2 \mathrm{mg} / \mathrm{L}$, bromide ion, $0.17 \mathrm{mg} / \mathrm{L}$ (adjusted to the highest concentration among the six fractions); incubation time, $24 \mathrm{~h}$ for most samples (see caption of Figure 2 for more details). The presence of free chlorine after $24 \mathrm{~h}$ was confirmed by the DPD method (APHA et al., 2005).

\section{Analytical methods}

The concentrations of 9 HAAs (those with $\mathrm{Cl}$ and/or $\mathrm{Br}$ ) were determined by GC/MS (QP2010Plus; Shimadzu) analysis with a DB-5ms capillary column $(30 \mathrm{~m} \times 0.25 \mathrm{~mm}$ i.d., $0.32 \mu \mathrm{m}$ film thickness; J\&W Scientific) after derivatization to the corresponding methyl esters (USEPA, 2003). 
The limits of quantification were $1 \mu \mathrm{g} / \mathrm{L}$ for tribromoacetic acid (TBA) and $0.25 \mu \mathrm{g} / \mathrm{L}$ for the other 8 HAAs. For this analysis, 1,2,3-trichloropropane was used as an internal standard. For comparison, THMs (with $\mathrm{Cl}$ and/or $\mathrm{Br}$ ) were also measured by GC/MS analysis using the same column as in HAA analysis following liquid-liquid extraction with pentane (APHA et al., 2005). The quantification limits of THMs were $0.5 \mu \mathrm{g} / \mathrm{L}$, and 1,2-dibromopropane was used as an internal standard for this analysis. DOC concentration was measured with a TOC analyzer (TOC-5000A; Shimadzu) in non-purgeable organic carbon (NPOC) mode. The detection limit for this analysis and the standard deviation for $200 \mu \mathrm{g} \mathrm{C} / \mathrm{L}$ were $30 \mu \mathrm{g} \mathrm{C} / \mathrm{L}$ and $4 \%$, respectively. All analyses were performed in duplicate.

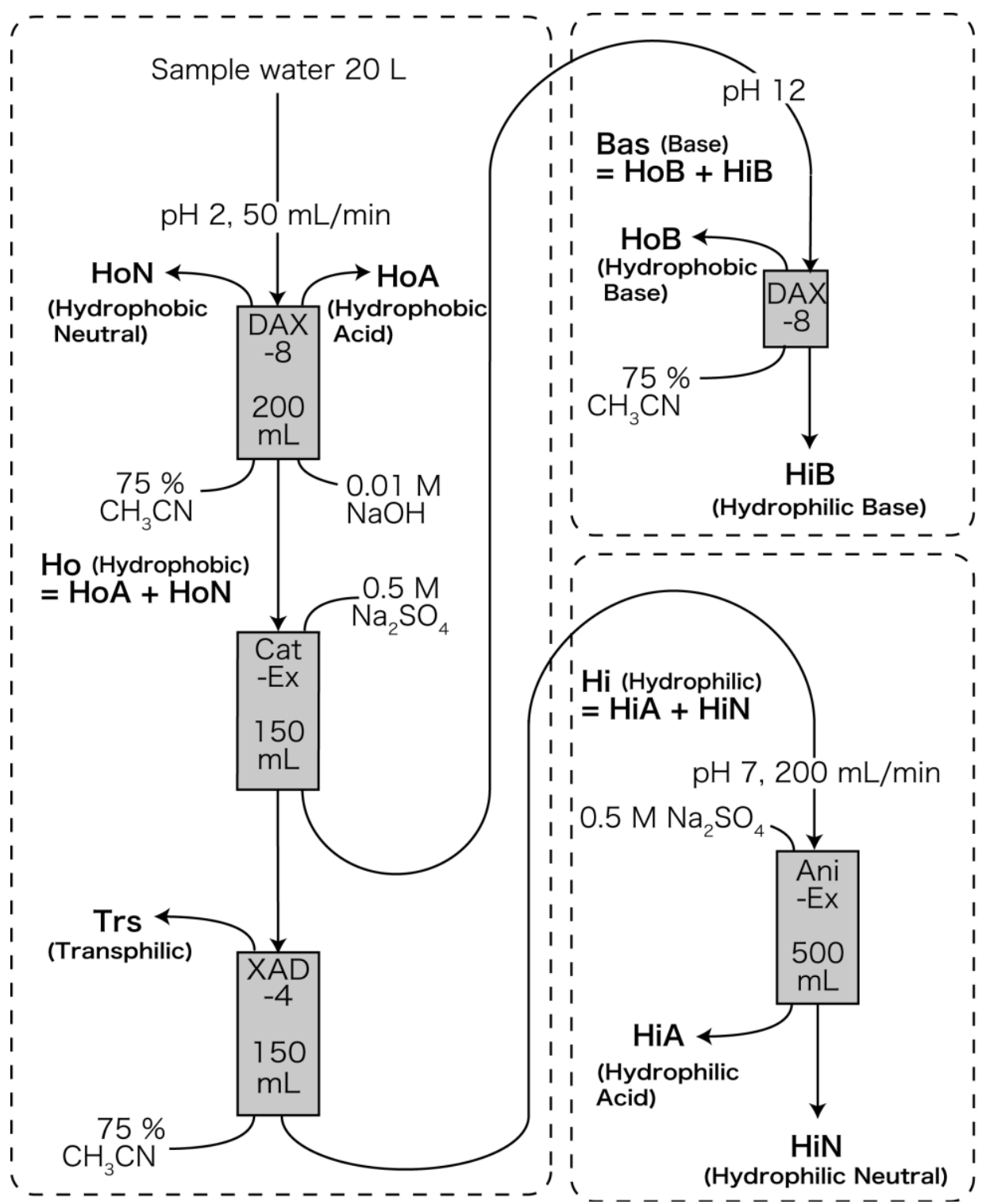

Figure 1. Schematic of DOM fractionation.

\section{RESULTS AND DISCUSSION}

\section{DOC profile}

Figure 2 shows the DOM profile along the treatment plant. The detailed DOM contents at each treatment step are also summarized in Table 1. To our knowledge, this is one of the most detailed 
DOM profiles along with a treatment train with ozone and GAC treatment obtained by a comprehensive fractionation technique. The hydrophilic fraction (i.e., HiA+HiN) was the dominant DOM fraction throughout the treatment process at this drinking water treatment plant, with percentages of $41 \%$ and $57 \%$ for the inlet water and after ozonation, respectively. The removal percentage of the hydrophilic fraction (Hi) was only $23 \%$, while hydrophobic $(\mathrm{HoA}+\mathrm{HoN})$ and basic compounds (Bas) were decreased by $72 \%$ and $67 \%$, respectively. The base fraction consisted mostly of hydrophilic compounds (i.e., the HoB fraction was negligibly small). These observations clearly indicated that the behaviors of different DOM fractions are different at various stages during drinking water treatment. It should be noted that the hydrophilic fraction remained dominant even following ozonation and GAC treatment. Thus, the combination of ozone and GAC may not be relevant in terms of DOC removal for source waters with high levels of hydrophilic compounds.

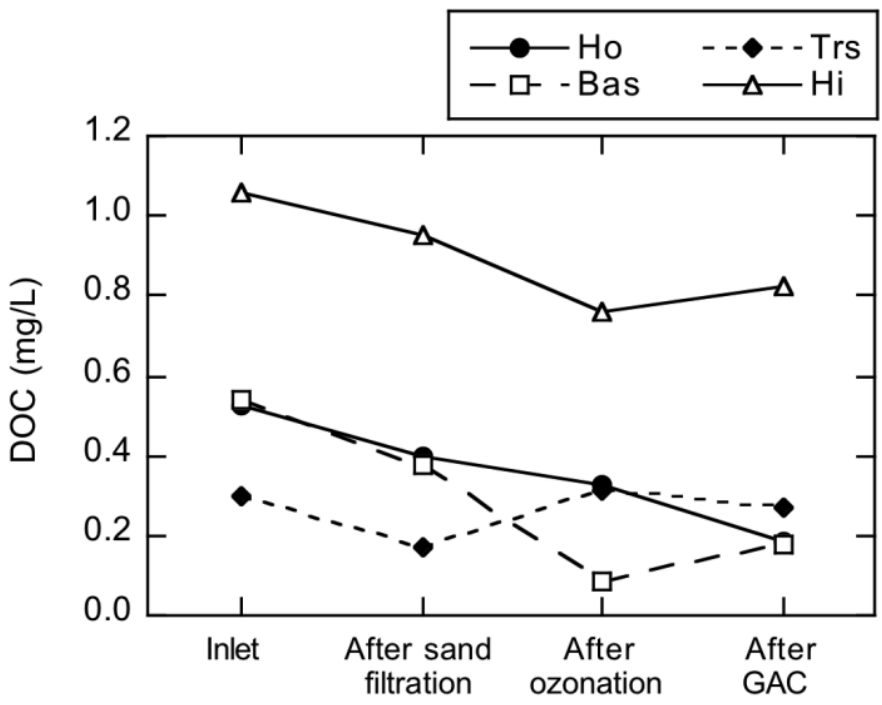

Figure 2. Summary of DOM profile along the drinking water treatment with ozonation and GAC (Ho: the sum of HoA and HoN; Hi: the sum of HiA and HiN).

Table 1. Detailed DOM profile along the drinking water treatment plant (Unit: mg C/L).

\begin{tabular}{|c|c|c|c|c|}
\hline & Inlet & $\begin{array}{c}\text { After rapid } \\
\text { sand filtration }\end{array}$ & $\begin{array}{c}\text { After } \\
\text { ozonation }\end{array}$ & $\begin{array}{l}\text { After } \\
\text { GAC }\end{array}$ \\
\hline HoA & 0.48 & 0.37 & 0.22 & 0.18 \\
\hline $\mathrm{HoN}$ & 0.17 & 0.03 & 0.11 & 0.00 \\
\hline Bas & 0.54 & 0.38 & 0.08 & 0.18 \\
\hline Trs & 0.30 & 0.17 & 0.32 & 0.27 \\
\hline $\mathrm{HiA}$ & 0.61 & 0.35 & 0.38 & 0.35 \\
\hline $\mathrm{HiN}$ & 0.45 & 0.61 & 0.38 & 0.47 \\
\hline Total & 2.55 & 1.90 & 1.49 & 1.43 \\
\hline
\end{tabular}

With regard to the various treatment steps, rapid sand filtration (coagulation and sedimentation) was effective for removal of five fractions other than HiN. The levels of removal for HoA, HoN, Bas, Trs, and HiA were 23\%, 82\%, 30\%, 43\%, and 43\%, respectively. Ozonation increased the DOC levels of HoN, Trs, and HiA, while it decreased those of HoA, Bas, and HiN. The increase in Trs was attributed to the formation of low molecular weight compounds from hydrophobic fractions. 
The HiA fraction increased by $9 \%$ probably due to the formation of more hydrophilic functional groups during oxidation reactions with molecular ozone and hydroxyl radicals. Higher HoN after ozonation has also been reported previously (Swietlik et al., 2004); based on the results of sizeexclusion chromatography, they suggested that the increase in $\mathrm{HoN}$ was mainly due to the formation of small hydrophobic compounds. After GAC treatment, only the Bas and HiN fractions increased presumably because of the release of organic compounds from the extracellular membranes of bacteria in GAC. HoN was removed completely in this treatment step. Although GAC was used to serve as biological activated carbon at this plant, no removal of hydrophilic compounds was observed with this treatment.

\section{HAA formation characteristics from different DOM fractions}

Figure 3 shows a summary of HAA formation per unit DOC from different DOM fractions. No mono-HAA (i.e., chloroacetic acid and bromoacetic acid) was detected in this series of experiments. HAA formation per unit DOC decreased for HoA, HoN, and Trs along the treatment train; HoA and Trs showed 58\% and 51\% removal, respectively, and HoN was removed completely after GAC. In contrast, that of HiA remained constant throughout the treatment process. The levels of HAA formation per unit DOC from HiN increased along the treatment train by $89 \%$. This change may have been due to the release of organic compounds from GAC, as mentioned above. Alternatively, the residual DOM may have had higher HAA formation potential. In addition, the ratio of dihaloacetic acids to trihaloacetic acids was higher in the Bas fraction. These observations indicated the dominance of aliphatic compounds in this fraction (Echigo et al., 2007). As the Bas fraction consists mostly of hydrophilic compounds, this observation was consistent with the pattern of HAA formation from DOM surrogates reported previously (Bond et al., 2009).

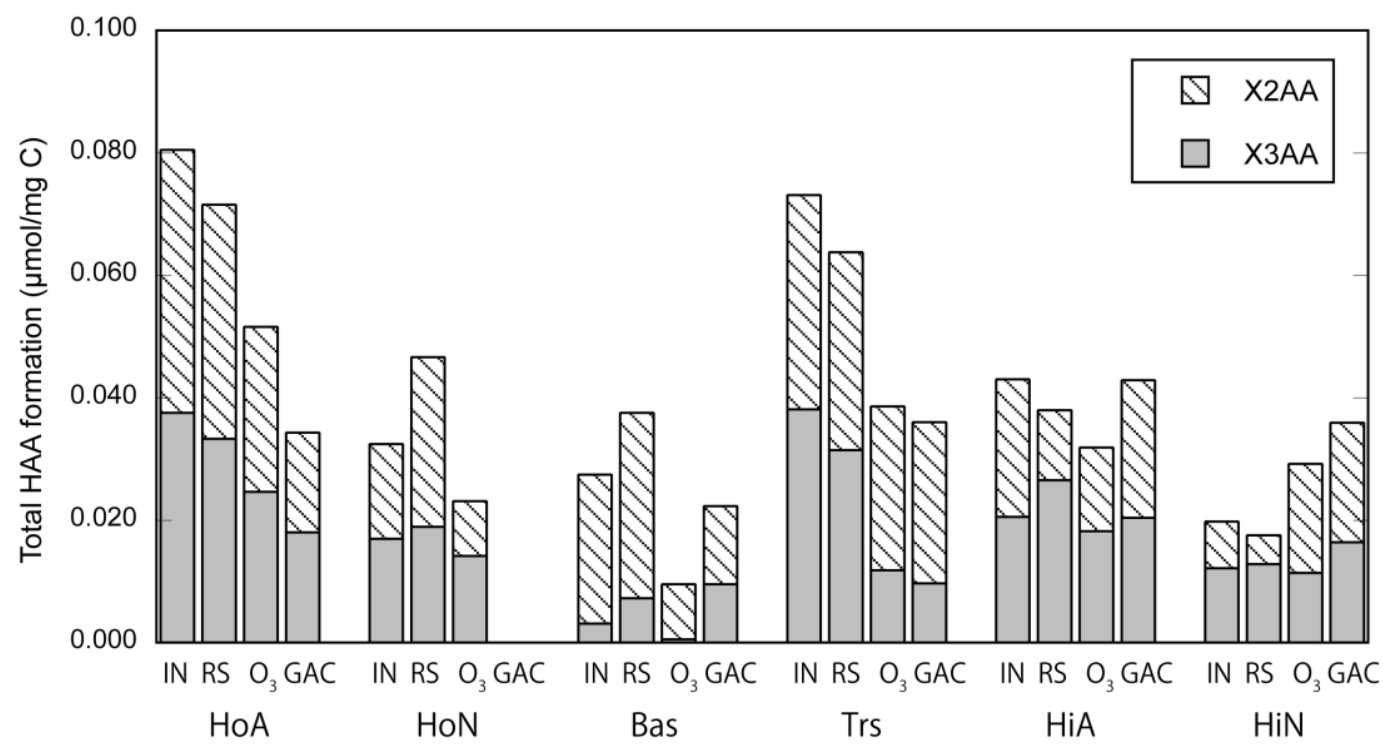

Figure 3. HAA formation potentials from different DOM fractions (Total concentrations of nine HAAs are presented here. Chlorination conditions: chlorine dose, $3 \mathrm{mg} / \mathrm{L}$; DOC, $2 \mathrm{mg} / \mathrm{L}$ (1.5 mg/L for the Bas sample after GAC because of lack of DOM amount recovered), bromide ion, $0.17 \mathrm{mg} / \mathrm{L}$; incubation time $24 \mathrm{~h} ; \mathrm{pH}, 7.0$. IN: inlet; $\mathrm{RS}$ : after rapid sand filtration; $\mathrm{O}_{3}$, after ozonation; GAC: after GAC treatment).

The differences in HAA formation among the DOM fractions after GAC were smaller than those after other treatment steps and the raw water, thus indicating very similar precursor structures among the different fractions.

Figure 4 shows a comparison of the subclasses of HAAs (in $\mu \mathrm{mol} / \mathrm{mg} \mathrm{C}$ ) along the treatment train. 
While the levels of chlorinated HAAs (HAAs with only $\mathrm{Cl}$ ) per DOC decreased, those of brominated (HAAs with only $\mathrm{Br}$ ) increased. This observation suggested a shift in the contents of HAAs from chlorinated to brominated species. As the bromide/chlorine/carbon matrix was adjusted at approximately same level in this study, this result was attributed to the changes in reactivity of DOM. It is likely that brominated HAAs were preferentially produced for the DOM after ozonation or GAC because bromination by $\mathrm{HOBr}$ (an intermediate species from the reaction of bromide and chlorine ions) occurs more rapidly than chlorination (e.g., Acero et al., 2005). As brominated compounds are known to more toxic than their chlorinated counterparts in general (Echigo et al., 2004) and among the HAAs (Plewa et al., 2002) regulations and monitoring focusing only on chlorinated HAAs may not be sufficient to guarantee the safety of finished water.

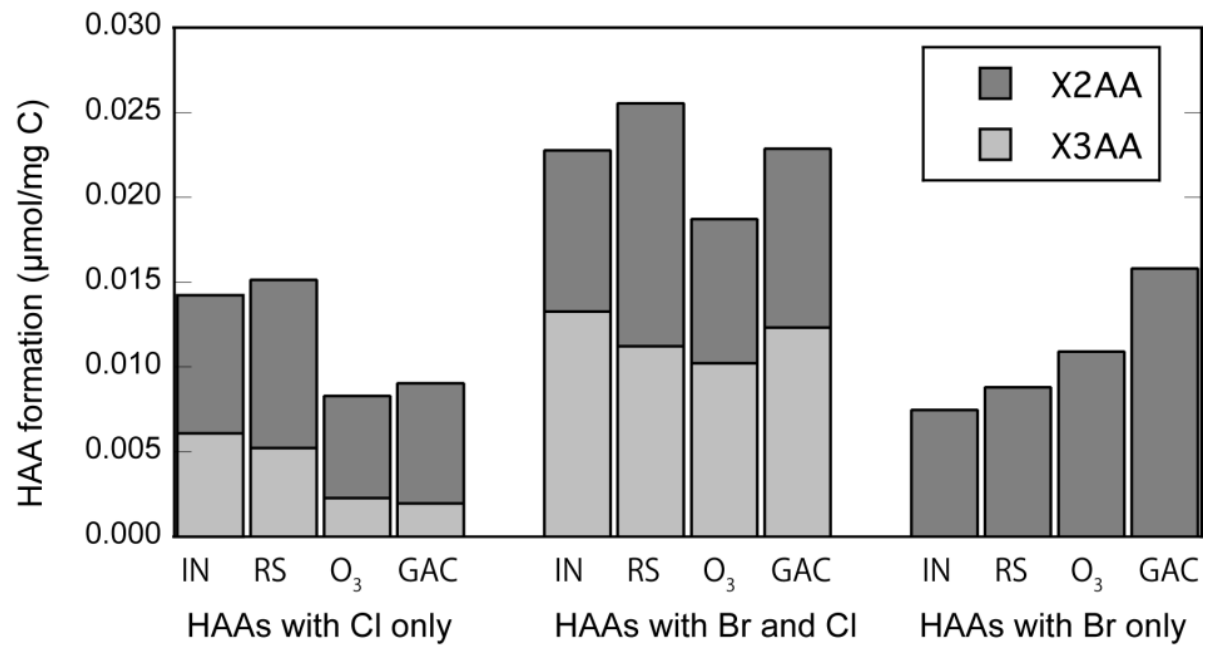

Figure 4. Types of HAAs produced at each treatment step (See caption of Figure 3 for conditions).

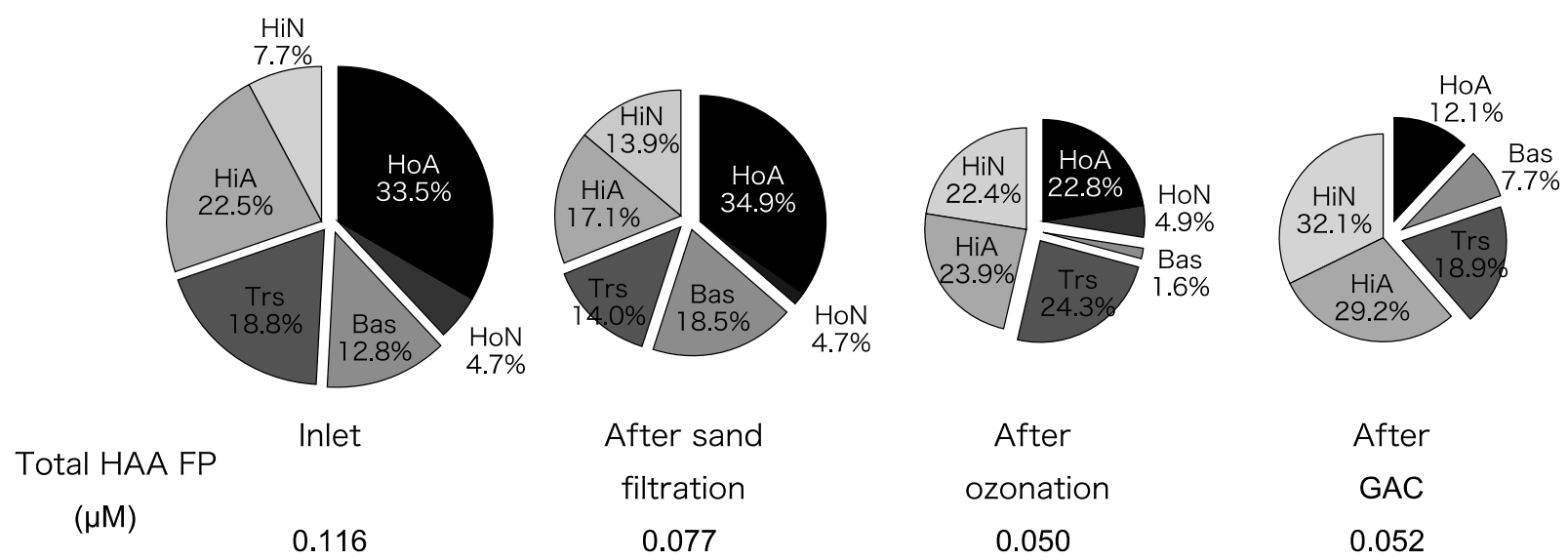

Figure 5. Relative contributions of DOM fractions to HAA formation potential at each treatment stage (Relative contributions were calculated with the DOC percentages and HAA formation potentials. That is, HAA formation potentials were weighted by DOC percentages).

Figure 5 shows the relative contributions of DOM fractions to HAA formation potential at each treatment step. The total formation potential decreased by $55 \%$ along the treatment train, while the relative contribution of the hydrophilic fractions increased from $30 \%$ to $61 \%$. Thus, the major 
contributor to HAA formation was different for the inlet sample and the sample after ozonation and GAC treatment. There are two major reasons for these results: (1) better removal of the hydrophobic fractions and (2) decreased yields of HAAs for hydrophobic fractions, but remaining constant for hydrophilic fractions.

These findings are important because most previous studies to identify the fraction important for DBP formation were conducted with source waters. Our results clearly indicated that the DOM content after treatment is completely different from that of the source water in terms of DBP formation, especially after ozone+GAC treatment (note: there was no HoN fraction after GAC) and that it is more appropriate to characterize DOM in the treatment train to identify the DOM fraction responsible for DBP formation.

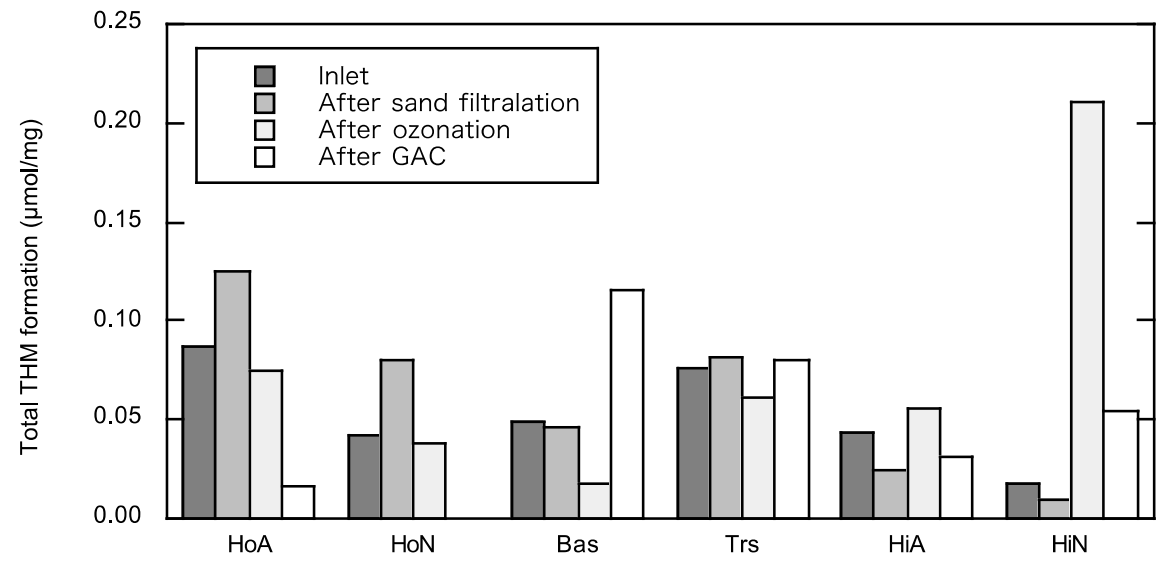

Figure 6. THM formation potentials from different DOM fractions (Total concentrations of four THMs are presented here. See caption of Figure 2 for chlorination conditions).

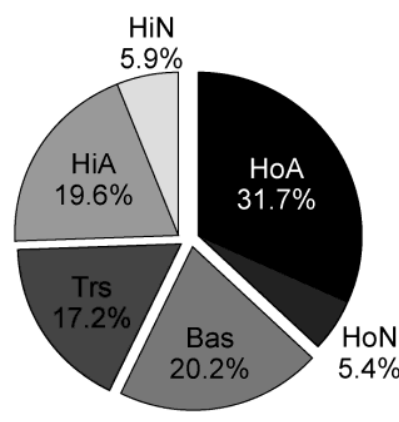

Inlet

Total THMFP

0.133

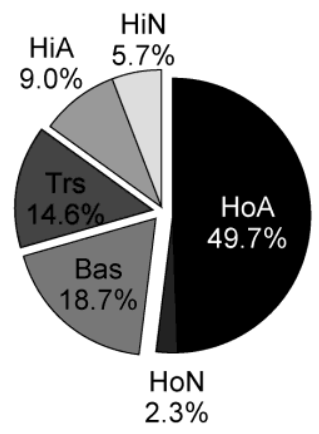

After sand filtration 0.094

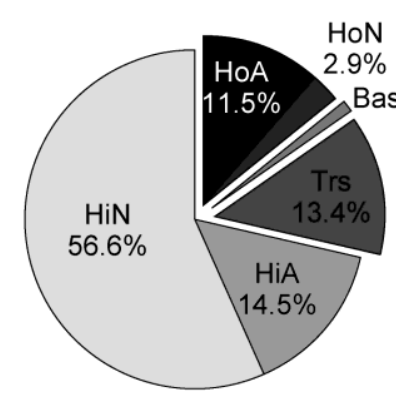

After ozonation

0.143

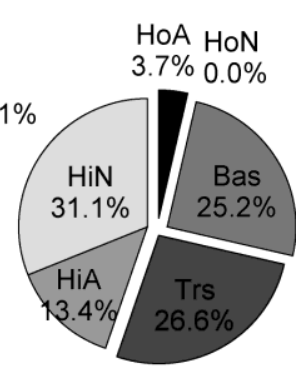

After GAC

0.082 $(\mu \mathrm{M})$

Figure 7. Relative contributions of DOM fractions to THM formation potential at each treatment step (Relative contribution was calculated from the DOC percentages and THM formation potentials. That is, THM formation potentials were weighted by DOC percentages). 
Figure 6 shows the THM formation potentials per unit DOC at each treatment step for DOM fractions. THM formation potentials of hydrophilic fractions decreased along the treatment process, but those of other fractions did not change or even increased. Similar to HAAs, these observations indicated the importance of hydrophilic fractions after treatment as the precursors of THMs. Figure 7 shows this more clearly. The contribution of hydrophilic fractions was very small (3.7\%), and this trend was similar to that of HAA formation potentials.

\section{CONCLUSIONS}

A comprehensive fractionation technique was applied to water samples obtained along a real drinking water treatment process with ozonation and GAC treatment to evaluate haloacetic acid (HAA) formation potentials of these DOM fractions. The results indicated only limited removal of hydrophilic fractions by ozonation and GAC treatment $(23 \%)$, while that of hydrophobic fractions was $72 \%$. The contribution of hydrophilic fractions to HAA formation increased from $30 \%$ to $61 \%$ along the treatment train due to better removal and lower reactivity after treatment. Similar trends were found for trihalomethanes. These observations suggested that the combination of ozonation and GAC treatment may not be relevant in terms of DOC removal and control of DBPs for source waters with high levels of hydrophilic compounds.

\section{REFERENCES}

Acero, J.L., Piriou, P., and von Gunten, U. (2005). Kinetics and mechanisms of formation of bromophenols during drinking water chlorination: Assessment of taste and odor development. Water Res., 39(13):2979-2993.

APHA, AWWA, WEF (2005). Standard Methods for the Examination of Water and Wastewater. 21th Edition. American Public Health Association/American Water Works Association/Water Environment Federation, Washington, DC.

Bond T., Henriet, O., Goslan, E.H., Parsons, S.A., and Jefferson, B. (2009). Disinfection byproduct formation and fractionation behavior of natural organic mater surrogates. Environ. Sci. Technol., 43: 5982-5989.

Echigo, S., Itoh, S., Natsui, T., Araki, T., and Ando, R., (2004). Contribution of brominated organic disinfection by-products to the mutagenicity of drinking water, Water Sci. Technol., 50(5): 321-328.

Echigo, S., Yano, Y., Jo, Y., and Itoh, S.(2007). Formation characteristics of haloacetic acids from common chemical structures in dissolved organic matter during chlorination, Environ. Eng. Res., 44: 265-273.

Imai, A., Matsunaga, K., and Nagai, T. (2003). Trihalomethane formation potential of dissolved organic matter in a shallow eutrophic lake. Water Res., 37(17): 4284-4294.

Kim, M.H. and Yu, M.J. (2005). Characterization of NOM in the Han River and evaluation of treatability using UF-NF membrane, Environ. Res., 97: 116-123.

Leenheer. J.A. (2004). Comprehensive assessment of precursors, diagenesis, and reactivity to water treatment of dissolved and colloidal organic matter. Water Sci. Technol.: Water Supply, 4(4):1-9.

Lee, W., Westerhoff, P., and Croué, J.-P. (2007). Dissolved organic nitrogen as a precursor for chloroform, dichloroacetonitrile, Nnitrosodimethylamine, and trichloronitromethane. Environ. Sci. Technol., 41:5485-5490.

Liang, L. and Singer, P. C. (2003). Factors influencing the formation and relative distribution of haloacetic acids and trihalomethanes in drinking water, Environ. Sci. Technol., 37: 2920-2928.

Lu, J., Zhang, T., Ma, J., and Chen, Z. (2009). Evaluation of disinfection by-products formation during chlorination and chloramination of dissolved natural organic matter fractions isolated from a filtered river water. J. Hazard. Mater., 162(1): 140145 .

Nagai, K., Aoki, S., Fuse, Y., and Yamada, E. (2005). Fractionation of dissolved organic matter (DOM) as precursors of trihalomethane in Lake Biwa and Yodo Rivers. Bunseki Kagaku, 54(9):923-928.

Plewa M.J., Kargalioglu Y., Vankerk D., Minear, R.A., and Wagner, E.D. (2002). Mammalian cell cytotoxicity and genotoxicity analysis of drinking water disinfection by-products, Environ Mol Mutagen. 40:134-142.

Swietlik, J., Dabrowska, A., Raczyk-Stanisławiak, U., and Nawrocki, J. (2004). Reactivity of natural organic matter fractions with chlorine dioxide and ozone, Water Res., 38: 547-558.

USEPA (2003). Method552.3: Determination of haloacetic acids and dalapon in drinking water by liquid-liquid microextraction, derivatization, and gas chromatography with electron capture detection. 